\title{
Emergence of Overconfidence Investor in Financial markets
}

\author{
Hiroshi TAKAHASHI ${ }^{1}$ Takao TERANO ${ }^{2}$ \\ ${ }^{1}$ Graduate School of Humanities and Social Sciences, Okayama University \\ ${ }^{2}$ Interdisciplinary Graduate School of Science and Engineering, Tokyo Institute of Technology
}

\begin{abstract}
This research utilizes the Agent-Based Model to clarify microscopic and macroscopic links between investor behavior and price fluctuations in the financial market. This analysis places focus on the role that investors' overconfidence plays in the financial market. As a result of this analysis, it has been found that overconfident investors are generated in a bottomup fashion in the market.
\end{abstract}

Keywords: Finance, Multi-Agent System, Behavioral Economics, Overconfidence, Inverse Simulation.

\section{Introduction}

In recent years, there has been rising interest in a field called behavioral finance which incorporates psychological methods in analyzing investor behavior. There are numerous arguments in behavioral finance that investors' decision making bias can explain phenomenon in the financial market which until now had gone unexplained [4][3].

However, there is also criticism that most such arguments in behavioral finance are simply ad hoc, applying decision making bias exogenously, and only introducing decision making bias conveniently in order to explain certain phenomenon.

With such underlying arguments, this analysis aims to show that decision making bias as defined by behavioral finance appears in a bottom-up fashion in the financial market. Above all, this research is undertaken with a focus on overconfident decision making which has been under the spotlight in recent years. Furthermore, this research inquires into the conditions under which transaction prices reflect fundamental values.

The next section of this paper explains the model utilized for this analysis, before analysis results are looked at in section 3 . Section 4 contains a summary.

\section{Model}

A computer simulation of the financial market involving 1000 investors was used as the model for this research, shares and risk-free assets being the 2 possible transaction methods [1][5]. Several types of investors exist in the market, each undertaking transactions based on their own stock calculations. This market is composed of 3 major steps, (1) generation of corporate earnings, (2) formation of investor forecasts, (3) setting transaction prices. The market advances through repetition of these steps [5].

\subsection{Negotiable Assets in the Market}

This market consists of both risk-free and risky assets. There is a financial security (as risky assets) in which all profits gained during each term are distributed to the shareholders. Corporate earnings $\left(y_{t}\right)$ are expressed as $y_{t}=y_{t-1}\left(1+\varepsilon_{t}\right)$, however they are generated according to the process $\varepsilon_{t} \sim N\left(0, \sigma^{2}\right)$ with share trading being undertaken after public announcement of profit for the term. Each investor is given common asset holdings at the start of the term with no limit placed on debit and credit transactions.

\subsection{Modeling Investor Behavior}

Investors in the market calculate transaction prices based on their own forecast for market tendency, taking into account both risk and return rates when making investment decisions. Each investor decides on the investment ratio $\left(w_{t}^{i}\right)$ of stock for each term based on the maximum objective function of $f\left(w_{t}^{i}\right)=r_{t+1}^{\text {int }, i} w_{t}^{i}+r_{f}\left(1-w_{t}^{i}\right)-\lambda\left(\sigma_{t-1}^{s, i}\right)^{2}\left(w_{t}^{i}\right)^{2}$. In this case, $r_{t+1}^{\text {inti } i}$ and $\sigma_{t-1}^{s, i}$ express the expected rate of return and risk for stock as estimated by each investor i. $r_{f}$ represents the risk-free rate. $w_{t}^{i}$ is the stock investment ratio of investor i for term $\mathrm{t}$ [2] [5].

Expected rate of return for shares $\left(r_{t+1}^{\text {int } i}\right)$ is calculated

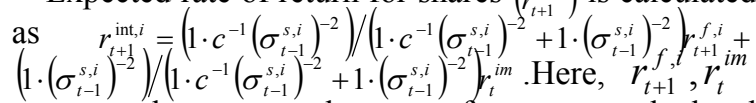
express the expected rate of return, calculated respectively from short-term expected rate of return, and risk and gross current price ratio of stock etc[2][5]. 
Short-term expected rate of return $\left(r_{t}^{f, i}\right)$ is obtained by $r_{t+1}^{f, i}=\left(\left(P_{t+1}^{f, i}+y_{t+1}^{f, i}\right) / P_{t}-1\right)\left(1+\eta_{t}^{i}\right), \quad\left(P_{t+1}^{f, i}, y_{t+1}^{f, i}\right)$ being the equity price and profit forecast for term $t+1$ as estimated by the investor. Short-term expected rate of return includes the error term $\left(\eta_{t}^{i} \sim N\left(0, \sigma_{n}^{2}\right)\right)$ reflecting that even investors of the same forecast model vary slightly in their detailed outlook.

Expected rate of return for stock $\left(r_{t}^{i m}\right)$ as obtained from stock risk etc. is calculated from stock $\operatorname{risk}\left(\sigma_{t-1}^{s, i}\right)$, benchmark equity stake $\left(W_{t-1}\right)$, investors' degree of risk avoidance $(\lambda)$, and risk-free rate $\left(r_{f}\right)$ in the equation $r_{t}^{i m}=2 \lambda\left(\sigma_{t-1}^{s}\right)^{2} W_{t-1}+r_{f}$.

\subsection{Equity Price Forecasting Method}

This analysis looks at (1) forecasting based on fundamental values, (2) forecasting based on trends, and (3) forecasting based on past averages .

The fundamental value of shares is estimated using the dividend discount model. Fundamentalists estimate the forecast stock price $\left(P_{t+1}^{f, i}\right)$ and forecast profit $\left(y_{t+1}^{f, i}\right)$ from profit for the term $\left(y_{t}\right)$ and discount rate of stock $(\delta)$ respectively as $P_{t+1}^{f, i}=y_{t} / \delta, y_{t+1}^{f, i}=y_{t}$.

Forecasting based on trends involves forecasting next term equity prices and profit through extrapolation of the most recent stock value fluctuation trends. This analysis looks at the 4 terms of 1 day, 5 days, 10 days, and 20 days for trend measurements.

Forecasting based on past averages involves estimating next term equity prices and profit based on the most recent average stock value. Average value was measured for the 4 terms of 1 day, 5 days, 10 days, and 20 days.

\subsection{Risk Estimation Method}

Stock risk is measured as $\sigma_{t-1}^{s, i}=s_{i} \sigma_{t-1}^{h}$. In this case, $\sigma_{t-1}^{h}$ is an index that represents stock volatility calculated from price fluctuation of the most recent 100 steps, and $s_{i}$ the degree of overconfidence. The presence of a strong degree of overconfidence can be concluded when the value of $s_{i}$ is less than 1 , as estimated forecast error is shown as lower than its actual value.

\subsection{Deciding Transaction Prices}

Transaction prices are set as the price where stock supply and demand converge $\left(\sum_{i=1}^{M}\left(F_{t}^{i} w_{t}^{i}\right) / P_{t}=N\right)$.

\subsection{Rules of Natural Selection}

The rules of natural selection come into play in this market on the basis of cumulative excess return for the most recent 5 terms [5]. The rules of natural selection are composed of the 2 steps of (1) appointment of investors who alter their investment strategy, and (2) alteration of investment strategy. With the alteration of investment strategy, existence of investment strategy alteration is decided based upon the most recent performance of each 5 term period after 25 terms have passed since the beginning of market transactions. In addition, things have been made easy for investors who decide to alter investment strategy to select an investment strategy with high cumulative excess return over the most recent 5 terms.

\section{Method of Analysis}

This analysis sets out to search for conditions by which the market value would reflect the fundamental value, after firstly undertaking a conditional search for investment strategy capable of acquiring excess return.

\subsection{Searching for Investment Strategy}

Firstly, analysis was made of the initial forecasting model ratio where there was a (1) high ratio of fundamental forecasting, and (2) a high ratio of trend forecasting. As the results of this analysis confirmed a strengthening degree of overconfidence in both cases, an analysis of (3) the random distribution of the initial ratio of each forecasting model was also undertaken to determine whether the same result could be obtained under different conditions. The results of this analysis are explained in detail below.

\section{When there is a High Ratio of Fundamental Forecasting}

As fundamentalists enforce a strong influence on the market value under these conditions, the market value is almost in concord with the fundamental value (Fig. 1). It can be confirmed that the number of fundamentalists is on the increase due to the rules of natural selection in regard to the transition of investor numbers (Fig.2). Looking at transition in the degree of overconfidence, a strengthening degree of overconfidence can be confirmed in the remaining investors as market transactions go forward.

\section{When there is a High Ratio of Trend Forecasting}

It was confirmed that when there is a high ratio of investors using trend forecasting, the market value deviated greatly from the fundamental value. The number of investors using trend forecasting also increases as such investors enforce a strong influence on the market value. This is thought to be the result of an investment environment in which different forecasting methods were applied to obtain excess 
return. On the other hand, it was confirmed that investors with a strong degree of overconfidence survive in the market even under these conditions.

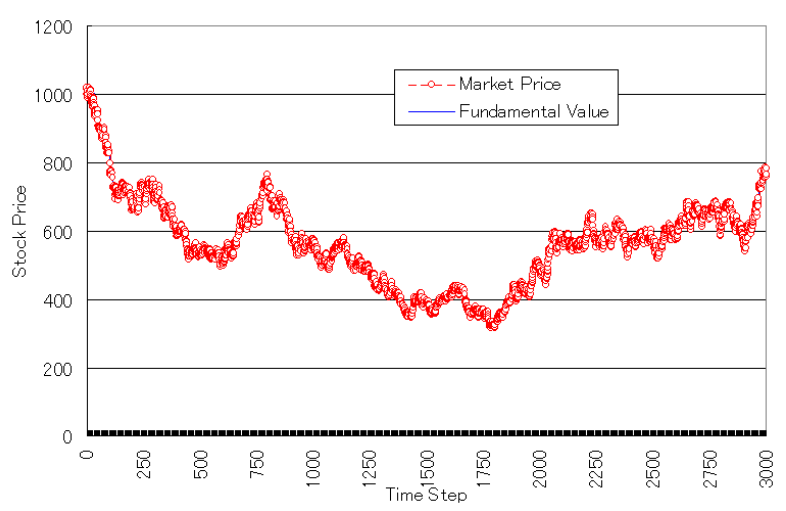

Fig. 1: Price Transition(Fundamentalist: Trend=500:500)

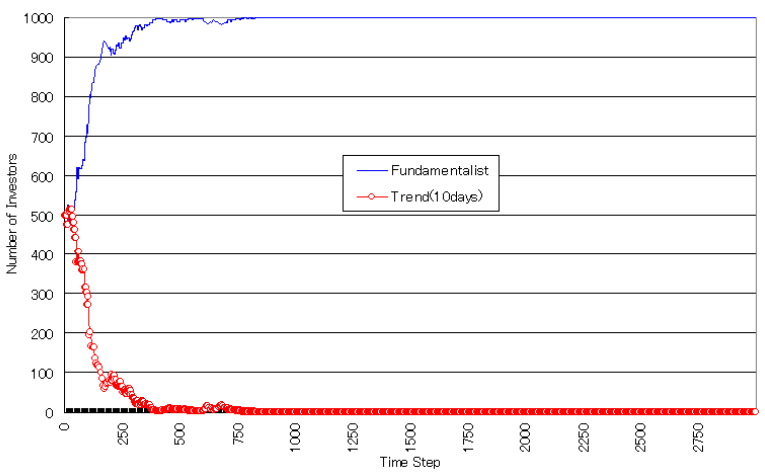

Fig. 2: Transition of Number of Investors (Fundamentalist: Trend $=500: 500$ )

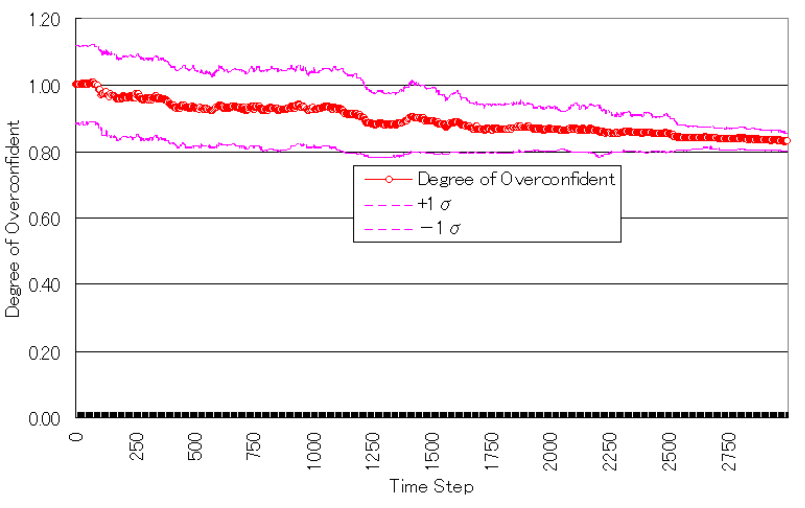

Fig. 3: Transition of Average Degree of Overconfidence (Fundamentalist: Trend $=500: 500$ )

\section{When the Initial Ratio is Applied Randomly}

A case in which the initial ratio of investors is applied randomly was analyzed next. Although the case example (Fig. 4) shown here indicates that numerous investors employ investment strategy based on the fundamental value, the forecasting model employed by market investors is dependant on the ratio of each type of investor etc, changing along with circumstances such as trend forecasting and the average value of past equity prices. In contrast, it has been confirmed that overconfident investors survive in the market even when a random initial value is applied for the degree of overconfidence (Fig. 5).

This interesting analysis result suggests the possibility of universality when survival trends of overconfident investors are compared with the forecasting model.

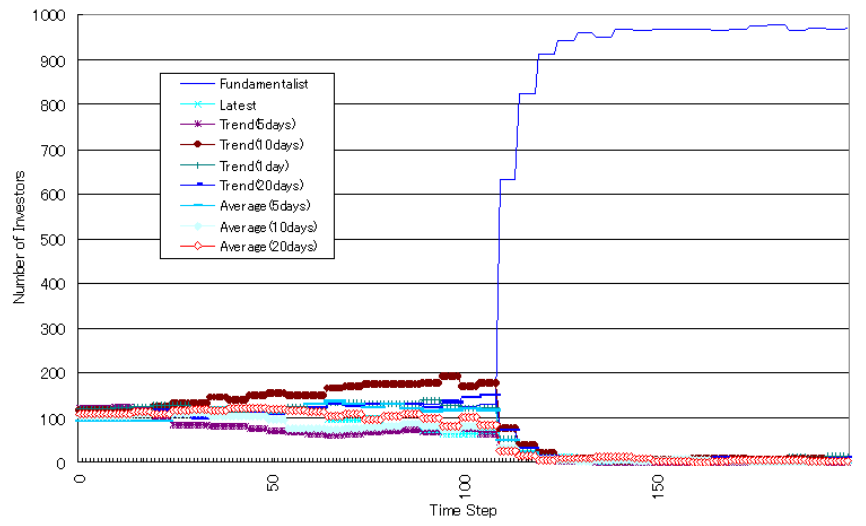

Fig. 4: Transition of Average Number of Investors (Random)

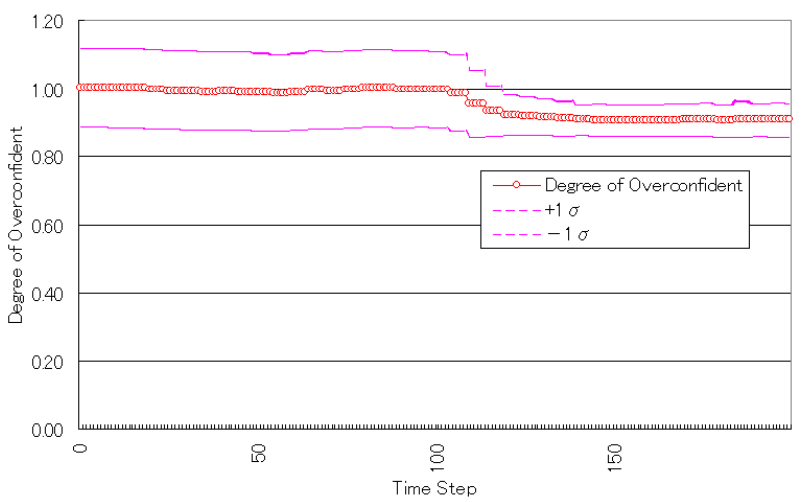

Fig. 5: Transition of Average Degree of Overconfidence (Random)

\subsection{Exploring Market Conditions}

This analysis endeavors to determine the conditions necessary for transaction prices to reach the fundamental value.

\section{Inverse Simulation Analysis Method}

Inverse Simulation Analysis consists of the following 3 steps. (1) Carry out 100 times a simulation with an investment period of 100 terms. (2) Calculate the index of deviation between transaction prices and the fundamental value for each simulation. (3) Set the calculated index as the adaptive value and select 100 simulation conditions (investors' forecasts, confidence). 
This analysis is undertaken through repetition of these 3 steps. The index $(q)$ of deviation between transaction prices and the fundamental value expresses the deviation ratio with the fundamental value and is specifically calculated as $q=E[x]^{2}+\operatorname{Var}[x]$. However, $P_{t}^{0} \quad$ represents the fundamental value $x_{t}=\left(P_{t}-P_{t}^{0}\right) / P_{t}^{0}$ for term $\mathrm{t}$.

\section{Conditional Search Results}

It can be seen from analysis results that transaction prices tend to approach the fundamental value when there is a high percentage of fundamentalist investors (Fig. 6) coupled with a strong degree of investor confidence (Fig. 7). In addition, transaction prices almost match the fundamental value in this case.

Traditional finance argues that market survival is possible for those investors able to swiftly and accurately estimate both the risk and rate of return on stock, achieving market efficiency. However, analysis results obtained here regarding the influence irrational investors have on prices suggests a different situation, pointing to the difficulty of market modeling which takes real conditions into account.

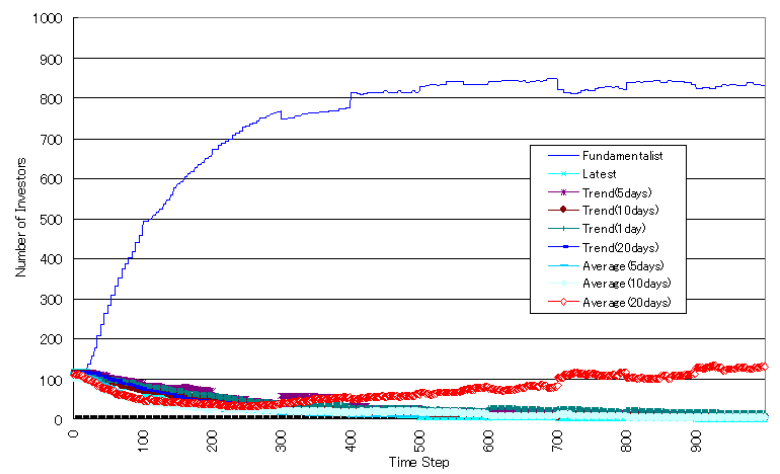

Fig. 6: Transition of Average Number of Investors (Inverse Simulation)

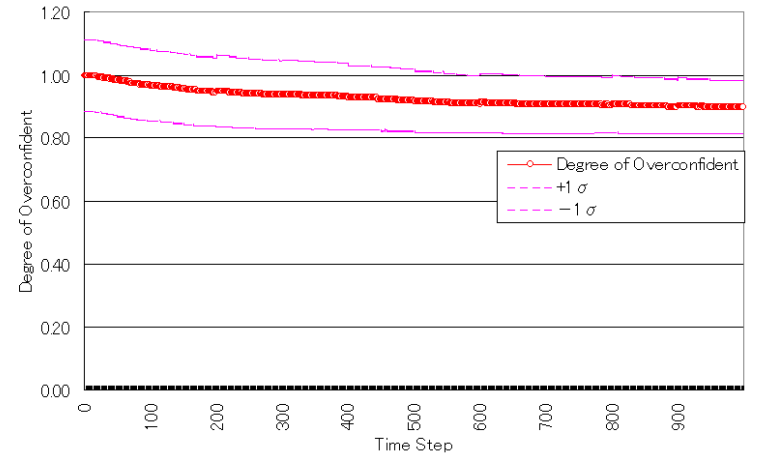

Fig. 7: Transition of Average Degree of Overconfidence (Inverse Simulation)

\section{Summary}

This paper utilizes the Agent-Based Model to analyze both microscopic and macroscopic associations in the financial market. In the process, it has been found that overconfident investors are generated in a bottom-up fashion in the market. Showing the existence of a survival mechanism as a characteristic feature of overconfidence in decision making is one of the significant achievements of this research. Furthermore, this research has also succeeded in showing that such characteristic features have the ability to contribute to a market which reflects fundamentals. Future issues include market modeling which takes more realistic conditions into account.

\section{Appendix}

List of the principle parameters used in this analysis.

M: Number of investors (1000)

$\mathrm{N}$ : Number of shares (1000)

$F_{t}^{i}$ : Total assets value for Term t $\left(F_{0}^{i}=2000\right)$

$W_{t}$ : Benchmark equity stake for term $\mathrm{t}\left(W_{0}=0.5\right)$

$w_{i}^{t}$ : Equity stake of investor i for Term $\mathrm{t}\left(w_{i}^{0}=0.5\right)$

$y_{t}$ : Profits generated during term $\mathrm{t}\left(y_{0}=0.5\right)$

$\sigma_{y}$ : Standard deviation of profit fluctuation $(0.2 / \sqrt{200})$

$\delta$ : Discount rate of shares $(0.1 / 200)$

$\lambda$ : Investors' degree of risk avoidance (1.25)

c: Distributed adjustment factor $(0.01)$

$\sigma_{n}$ : Standard deviation of data dispersion for short term expected rate of return on shares $(0.01)$

$S_{i}$ : Coefficient to express degree of confidence (uniform random number of 0.8-1.2)

\section{References}

[1] Arthur, W. B., Holland, J.H., Lebaron, B., Palmer, R.G. and Taylor, P.: Asset Pricing under Endogenous Expectations in an Artificial Stock Market, The Economy as an Evolving Complex System II, Addison-Wesley, pp.15-44 (1997).

[2] Black, F. and Litterman, R.: Global Portfolio Optimization, Financial Analysts Journal, September-October, pp.28-43 (1992).

[3] Levy, M., Levy, H. and Salomon, S.: Microscopic Simulation of Financial Markets, Academic Press (2000).

[4] Shleifer, A.: Inefficient Market $\}$,Oxford University Press[2000].

[5] Takahashi, H. and Terano, T.: Agent-Based Approach to Investors' Behavior and Asset Price Fluctuation in Financial Markets, Journal of Artificial Societies and Social Simulation, 6, 3 (2003). 